\title{
Effect of Warning System on Interactive Driving Behavior at Unsignalized Intersection under Fog Conditions: A Study Based on Multiuser Driving Simulation
}

\author{
Yunfan Zhang, Xuedong Yan (iD, Jiawei Wu, and Ke Duan \\ MOT Key Laboratory of Transport Industry of Big Data Application Technologies for Comprehensive Transport, \\ School of Traffic and Transportation, Beijing Jiaotong University, Beijing 100044, China \\ Correspondence should be addressed to Xuedong Yan; xdyan@bjtu.edu.cn
}

Received 6 May 2020; Accepted 16 December 2020; Published 30 December 2020

Academic Editor: Ludovic Leclercq

Copyright (C) 2020 Yunfan Zhang et al. This is an open access article distributed under the Creative Commons Attribution License, which permits unrestricted use, distribution, and reproduction in any medium, provided the original work is properly cited.

\begin{abstract}
The intersection collision warning system (ICWS) is an emerging technology designed to assist drivers in avoiding collisions at intersections. ICWS has an excellent performance in reducing the number of collisions and improving driving safety. Previous studies demonstrated that when visibility was low under fog conditions, ICWS could help drivers timely detect hazardous conflicting vehicles. However, the influences of ICWS on interactive driving behavior at unsignalized intersection between different vehicles have barely been discussed. This study aimed to investigate the patterns of drivers' interactive behaviors with the assistance of a new kind of ICWS under fog conditions based on Multiuser Driving Simulation. The Multiuser Driving Simulation allowed multiple drivers to operate in the same simulation scenario at the same time, and it could capture drivers' interactions preferably. Forty-eight licensed drivers completed the driving simulation experiment in three fog conditions (no fog, light fog, and heavy fog) and two warning conditions (warning and no warning), in which the drivers drove in a straight-moving situation at unsignalized intersection with potential collision risks caused by the encounter of two vehicles. The results verified that warning and fog conditions were significant factors that affected the interactive driving behavior in the unsignalized intersection collision avoidance process, including the driver's decision, TTC of action point, average acceleration (deceleration) rate, and postencroachment time. Compared to conditions without ICWS, the ICWS could help drivers make collision avoidance actions earlier and change the speed more smoothly. In addition, with the help of Multiuser Driving Simulation, associations between decision driving behaviors of vehicles were discussed with caution. The results revealed the decision-making mechanism of drivers in the process of interaction with other drivers. Under the influence of fog, interactive driving processes were fraught with increased risk at unsignalized intersection. However, the ICWS helped drivers interact more harmoniously, safely, and efficiently. The findings shed some light on the further development of ICWS and the study on interactive driving behavior.
\end{abstract}

\section{Introduction}

The intersections are the crucial nodes in the road network and also the sections with high incidence of serious traffic accidents, especially the unsignalized intersection. The traffic statistics shown that there were about $40 \%$ traffic accidents occurring at the intersections, where $28 \%$ were unsignalized intersections accidents and $12 \%$ were signalized intersections accidents [1]. Instead, the drivers dynamically decide to speed up or slow down when the vehicles gradually approach each other [2]. This process is fraught with insecurity due to the uncertain personalized driving behavior.
Adverse weather conditions greatly increased the risk in this process, which had significant impacts on visibility distance, driving behavior, vehicle performance, pavement conditions, travel demand, traffic flow characteristics, and traffic safety [3]. Among different adverse weather conditions, fog was the most hazardous conditions for drivers [4]. According to the National Highway Transportation Safety Administration's (NHSTA) Fatality Analysis Reporting System (FARS), fog/smoke contributed as a major factor in 3729 fatal crashes that occurred in the United States between 2000 and 2007 [5, 6]. Most previous studies about driving performance in fog had focused on drivers' speed control 
ability [3, 7, 8] and lane-keeping ability [8] in some certain foggy scenarios. However, few studies have analyzed driving performance in fog at unsignalized intersections. Foggy weather could result in a reduction in visibility of unsignalized intersection, which was a direct accident cause of over $90 \%$ of all crashes at unsignalized intersections [9]. Appropriate mitigation strategies were necessary since the reduced visibility had a significant impact on driving behavior. Active safety technologies that could alert drivers to various risk factors, were introduced to heighten driving safety in unsignalized intersection [10].

Many scholars have proposed a variety of auxiliary strategies about active safety technologies at intersections. For example, ICWS (intersection collision warning system) $[11,12]$ could detect all vehicles approaching the intersection on vehicles' real-time positions and speed with sensors (e.g., radar) equipped in vehicles or base station at intersections to warn drivers of hidden dangers when the visibility was restricted. Utilizing this method to gather information about vehicle's speed and location could model the real-time crash process [13] or compute the collision probability in an intersection. The outcomes of modelling and computing could be applied to the main indicators to issue warning, usually using TTC (time to collision) and TTA (time to avoidance) [14], to alert the driver of an imminent collision. Some studies paid special attention to warning drivers about the presence of surrounding trucks [15], emergency vehicles, and even roadside infrastructure [16]. Recently, methods relied on $\mathrm{V} 2 \mathrm{~V}$ (vehicle to vehicle) technologies that could transmit safety-related information from one vehicle to surrounding vehicles by direct wireless communication, provided a more accurate approach for ICWS [17].

ICWS's advantages have been demonstrated; it could help drivers deal with urgent situations in the critical intersection and enhance drivers' collision avoidance performances [11, 18-21]. Experiments, conducted by Chang et al. (2009), have shown that the driving performance of young people was affected by a collision warning system. What is more, the warning system assisted in making the reaction time of drivers shorter [19] and the accident rate lower [22]. In the study on the warning effect of the red-light violation, some scholars found that the warning signal of red light in the vehicle could increase the stopping frequency of drivers when switching to yellow lights and reduce the driving speed $[23,24]$. In the case of unsignalized intersections, the advantage of ICWS becomes more obvious since the unsignalized intersections are filled with more inevitable conflicts. ICWS could advance the driver's response time [1], which got the driver more time to avoid the collision at unsignalized intersections. For the warning timings, Kenji Tanaka et al. carried out experiments of issuing point of collision avoidance warnings at intersections and proved that the issuing point of the warning was mainly dependent on the distance between the vehicle and the intersection [25]. For the modality of warning, visual warning [26], auditory warning [3, 27, 28], and tactile warning have aroused extensive discussions. Compared to the visual warning and tactile warning, auditory warning provided omnidirectional sound massages for drivers no matter where they were focused on, which led to less interference with the driving task and less mental overload. However, auditory warnings were hard to ignore; these were more prone to cause annoyance which could impair compliance especially after false alarms [29]. According to the experiment conducted by Felix Schwarz [30] and Wolfgang Fastenmeier [26], the visual warning was observed to have advantages over the other warning designs concerning gaze and braking reaction times, passing speeds, and collision rates. Visual presentation of warnings was more effective than auditory alternatives [31].

However, most of these methods simply give information about the risk of driving, such as icons; few warning systems attempted to warn drivers quantitatively. For the purpose of improving the safety of unsignalized intersections, our study also put forward a visual collision warning system assisted by the HUD (head-up display), which would provide drivers with a quantified, accurate, and real-time updated warning about the potentially possible collision. Automotive head-up displays (HUDs) could reduce the driver's eye-off-the-road time (EoRT) and reaccommodation demands by presenting visual information within the driver's forward field of view (FoV), at a focal plane further into the forward scene. Some studies have empirically demonstrated the positive effects of HUDs in terms of performance of primary and secondary driving tasks, driver distraction, and workload [32]. A driving simulation experiment would be conducted to verify the effectiveness of this kind of unsignalized intersection warning system in foggy weather. Compared to empiricism, our results were more scientifically based. In general, these kinds of ICWS efficacy test research were mostly achieved by one driving simulator. For simplicity, a lot of assumptions, such as constant speed and constant deceleration, were made in these previous efficacy tests. It was well known that the vehicle must slow down or stop to avoid accidents, but in the previous efficacy test, it could not simulate the real scene exactly because one of the conflicting vehicles was controlled by the system. In reality, drivers could avoid collisions through a variety of behaviors, more than braking. Therefore, in order to explore the effectiveness of the ICWS more effectively, this research considered using two-linked driving simulators to simulate a more realistic experimental scene, where two subjects could have stronger interactions than the ordinary driving simulator.

From previous studies, multiple linked driving simulation experiments were a relatively immature research field. Houtenbos et al. used two linked driving simulators to examined the effects of an audiovisual display that provides warning information [33]. However, in Houtenbos's experiments, one simulator was driven by the subject and the other by the experimenter to create more abundance scenarios. It meant that the multiple linked driving simulator has not been used to its fullest extent. In this study, scenarios were set up where the subject would be able to drive more freely and the interaction between the subjects was stronger. Driving performances were complex and diverse. Even drivers from different directions had different performances. 
Accordingly, this driving-simulator-based study was conducted to investigate how straight-moving drivers perform under different conditions at unsignalized intersection. A new form of ICWS was proposed, and its efficacy would be studied on the basis of driving simulation experiments. In addition, for the purpose of testing, the property of the ICWS in adverse weather-fog weather (light fog and heavy fog) was introduced as an important factor in the experiment.

\section{Method}

2.1. Apparatus. The equipment used in this experiment was the Multiuser Driving Simulation (MDS), which was developed by Beijing Huiyitiancheng Digital Technology Co., Ltd. MDS system was a driving simulation system with high integration, excellent performance, and realistic effect. It could support driving simulation experiments on various urban traffic environments under laboratory control according to different experimental purposes and conduct corresponding experimental results. The followings are the main features of MDS:

(1) Support multiuser networking: online simulation was a domestic initiative with international leading technology, and the number of users could be expanded freely.

(2) Rich traffic events: MDS had an expanding traffic event library, various event trigger systems, and programmable scripts to build complex traffic events. MDS broke through the realization of visual editing of scene variables (including an unlimited map, traffic facilities, vehicles, pedestrians, signal system, environment, and trigger events).

(3) Support mass simulation analysis: MDS could record simulation data in the whole process and support data export in various formats.

The system consisted of ten single driving simulators, which were connected by a server, as shown in Figure 1. This experiment used two of these linked driving simulators. Each single simulator was equipped with a driver seat, an automatic gearbox, a gas pedal, a brake pedal, and three screens to project the front-view driving scenarios with a 120-degree view, and so forth.

2.2. Subjects. A total of 48 subjects participated in this research. In order to eliminate the interference of the internal differences of the subjects, this experiment intentionally recruited drivers who were of the same gender (all of them were male) and age (average age was 24, ranging from 22 to 30 years old). Every subject held a valid driver's license in China, and the driving experience of each subject was between 2 and 4 years. Subjects were divided into pairs of 24 groups, in which two drivers in each group would enter the same scene and encounter at the same unsignalized intersection. The experiment lasted about $60 \mathrm{~min}$ in total, and each subject received 300 Chinese RMB (about 51 US dollars) after the experiment was completed.

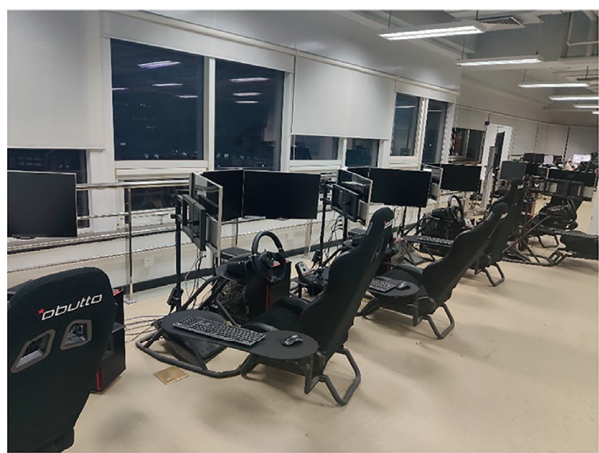

Figure 1: The Multiuser Driving Simulation.

2.3. Scenarios Design. There are 6 experimental scenarios: "no fog" and "warning," "light fog" and "warning," "heavy fog" and "warning," "no fog" and "no warning," "light fog" and "no warning," and "heavy fog" and "no warning." The scene where the two straight-moving vehicles would encounter in an unsignalized intersection was designed.

2.3.1. Road Network Design. Considering the adequacy and integrity of data, three consecutive unsignalized intersections were set up. The scenario was designed as a bidirectional straight rural road with a speed limit of $40 \mathrm{~km} / \mathrm{h}$, and the total length of the roads was $3000 \mathrm{~m}$ (the blue vehicle gone along the blue line, and the red vehicle gone along the red line) as shown in Figure 2. There was no traffic flow in the whole scene except for the two subject vehicles. The roads were all at the same level, and there were no fixed objects blocking the driver's sight.

In order to enable the two vehicles to reach the conflict point of the intersection at the same time, each driver was required to stop at $250 \mathrm{~m}$ in front of each intersection, and then two subjects in each group would start driving simultaneously according to the instruction from the corresponding experimenter for each subject.

For the purpose of studying the efficacy of the ICWS under different fog conditions, three different levels of fog conditions, no fog (visibility was greater than $600 \mathrm{~m}$ ), light fog (visibility was $150 \mathrm{~m}$ ), and heavy fog (visibility was $60 \mathrm{~m}$ ), were set. Road environments under different fog levels are shown in Figure 3.

2.3.2. ICWS Design. The system was designed to provide a "broad and clear view" for drivers whose visibility is limited by foggy weather at unsignalized intersections, which meant that drivers could learn the information of the conflicting vehicle within the boundaries of an intersection by ICWS, even if drivers could not see it with their naked eye. For example, when vehicle $V_{1}$ approaches the intersection, if the system detected that it has reached the point $\mathrm{DxD}_{\mathrm{x}}$ as shown in Figure 4, the system would detect whether there were other vehicles approaching the intersection within the range of the intersection. When the other vehicle $V_{2}$ was detected, $\Delta T$ was calculated: 


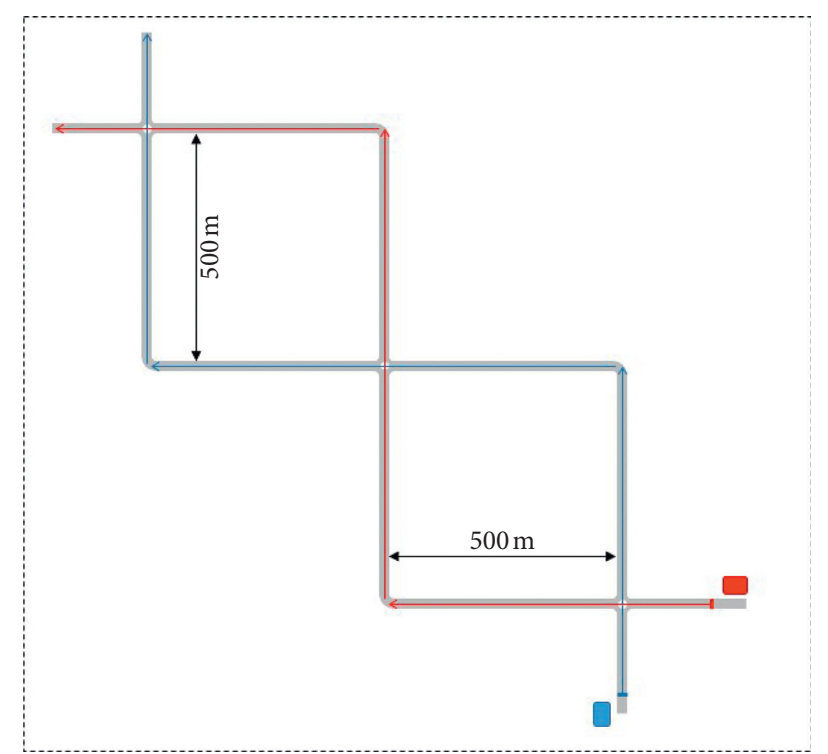

FIGURE 2: Foundation road network and the route of each vehicle.

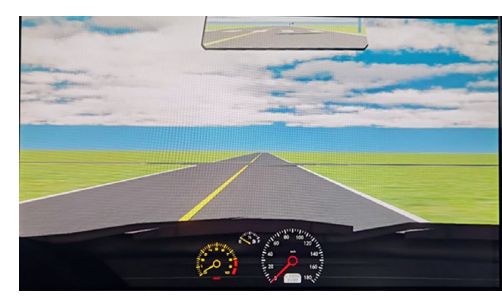

(a)

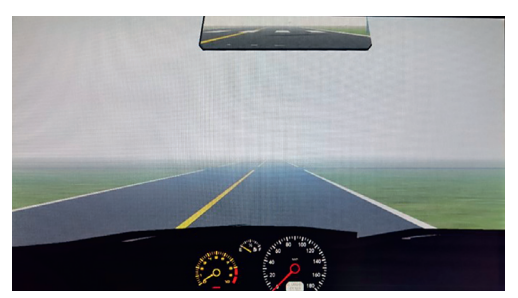

(b)

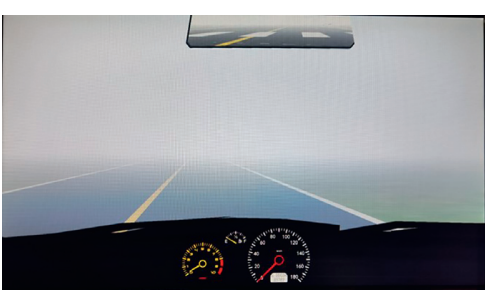

(c)

FIgURE 3: Driving interface in different fog conditions. (a) No fog. (b) Light fog. (c) Heavy fog.

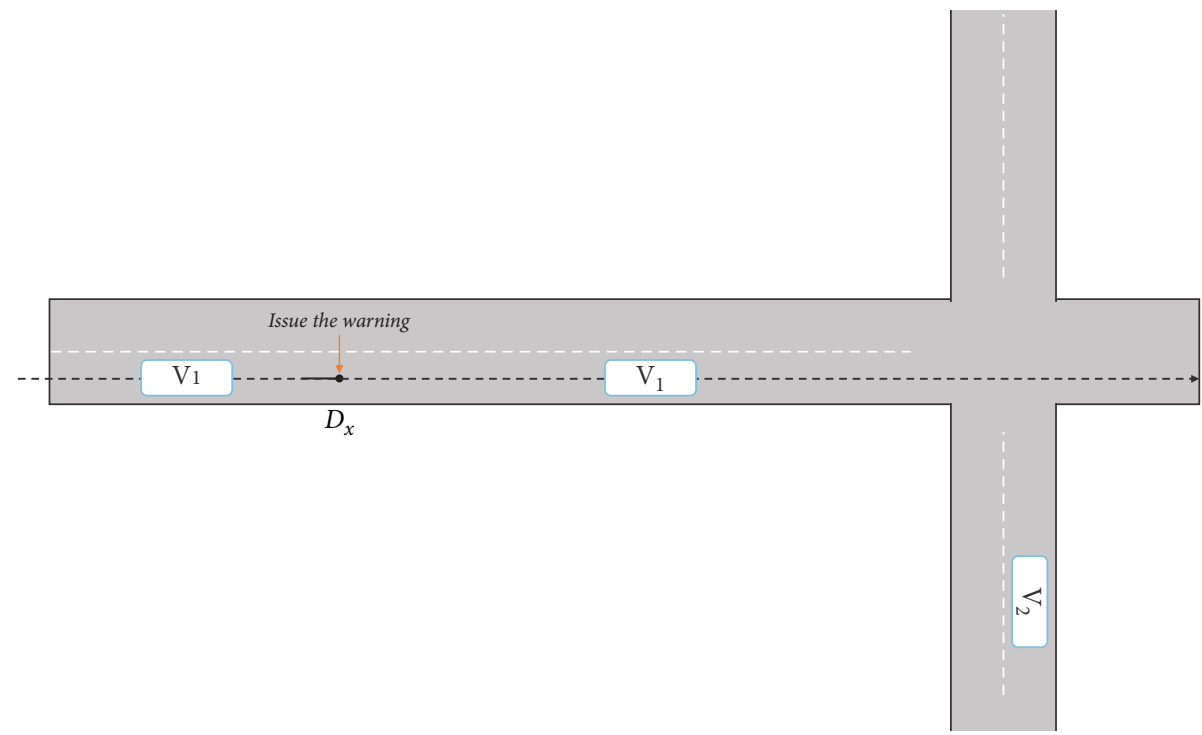

FigURE 4: The process of the driver approaching intersection. 


$$
\Delta T=\left|\frac{X_{1}}{V_{1}}-\frac{X_{2}}{V_{2}}\right|,
$$

where $\Delta T$ is the $\Delta$ TTC difference value of the two vehicles' time to the intersection and $X_{1}$ and $X_{2}$ are the distance of $V_{1}$ and the right $V_{2}$ to the intersection, respectively. $V_{1}$ and $V_{2}$ are the speed of V1 and V2, respectively.

If $\Delta T<5.0 \mathrm{~s}$ [14], the system would determine that there was a high probability of a collision. At the moment, the warning system would feed the conflict state back to the driver through HUD based on the collected information in order to remind the driver of the danger from the conflicting vehicle at this intersection.

The interface of the warning system could update the location of other vehicles and its distance to the intersection in real time. When the system detected the potential conflict, the warning interface would automatically fire bullets at the lower right corner of the display, as shown in Figure 5. And the image would automatically disappear after the conflict was eliminated.

When or where the warning system released warning information to the driver could significantly affect the driver's subsequent collision avoidance behavior. The setting principle of $D_{x}$ was to ensure that the driver had sufficient reaction time. The collision rate of vehicles significantly decreased when the release time of warning information was increased from 4.0 seconds to 5.5 seconds and also pointed out that 5.5 seconds was the optimal warning condition scheme [34]. When determining the release time of warning information, the reaction time of the driver and the effective time of collision avoidance decision reserved for the driver should be taken into account [35]. Reaction time was set at $2.5 \mathrm{~s}$ according to the previous study $[3,36]$. The calculation formula of the warning release position is as follows:

$$
D_{x}=L_{\mathrm{sd}}+\frac{T_{r} V_{0}}{3.6}+\frac{T_{w} V_{0}}{3.6},
$$

where $D_{x}$ donates the position where the warning system releases; $\mathrm{L}_{\mathrm{sd}}$ donates the safe stopping distance, $L_{\mathrm{sd}}=\left(V_{0} / 3.6\right) / 2 a^{2}, a=1.2 \mathrm{~m} / \mathrm{s}^{2} ; \operatorname{Tr} \mathrm{T}_{\mathrm{r}}$ is the reaction time $\left(T_{r}=2.5 \mathrm{~s} T_{r}=2.5 \mathrm{~s}\right) ; \mathrm{V}_{0}$ is the speed limit of the section $\left(V_{0}=40 \mathrm{~km} / \mathrm{h} V_{0}=40 \mathrm{~km} / \mathrm{h}\right)$; and $T_{w}$ is the time that the warning needs to be issued in advance $\left(T_{w}=5.5 \mathrm{~s}\right)$ $\left(T_{w}=5.5 \mathrm{~s}\right)$. The formula eventually gives the approximate $\mathrm{D}_{\mathrm{x}}$ of $150 \mathrm{~m}$.

2.4. Procedure. Upon arrival, each subject was briefed on the content and requirements of the experiment first and signed an informed consent form (per IRB, Institutional Review Board). Before the formal start of the experiment, subjects needed to be trained, including attempting to change speed, change lanes, turn, start and stop, and other driving skills. In addition, drivers would also learn the warning system. The scene used for training was a section of road which is similar to the experimental scene, including intersections and straight sections. Subjects were then advised to drive and behave as they normally would and to adhere to traffic laws as they would in real-life situations. Subjects were also notified that, during the experiments, if they had strong dizziness and other physical discomforts, the driver could quit the experiment at any time. After preparation and training, the driver could start the experiment formally. Each experiment involved two subjects, who were placed in position according to their ID number, experimental group number, and machine number. Each experimental group entered six scenes in turn to complete the driving task where the three fog conditions (no fog, light fog, and heavy fog) and two warning conditions (warning, no warning) occurring in a random sequence (to eliminate the learning effect). Each scene lasted for about 5 minutes and the experimental driver could rest for 5 minutes after completing the driving task of each scene. Besides, two subjects cannot communicate with each other during the whole process. After completing the driving tasks, the subjects were organized to fill in the questionnaire.

2.5. Data Analysis Methods. During the experiment, the simulator data were sampled at $30 \mathrm{~Hz}$. The data within $200 \mathrm{~m}$ from the intersection are selected as the analysis objects. 432 cases of intersection driving data were obtained. A total of 399 cases were analyzed due to the exclusion of those who did not follow the instruction of the experimenter.

\subsubsection{Definition of Critical Stages of Drivers' Driving Inter-} action Process. Drivers' interaction process in unsignalized intersection was divided into three continuous stages. Figure 6 illustrates the relationship among the three stages. The first stage is called the "approaching stage" during which drivers noticed the unsignalized intersection and headed straight for it. The following stage is the "decision stage." In this stage, drivers receive the warning and generate collision avoiding intentions, then synthetically judge the acquired information, and are ready to make the initial collision avoidance decision. Until the "action point," vehicles speeds change. Therefore, the "action point" is the point at which vehicles' speed starts to change. The third stage is the "adjustment stage". In this stage, drivers execute the collision avoidance decision and drivers take the initial action. Then, they will continue to adjust their speed and drive towards the intersection. It is worth noting that some drivers may not make any decisions and there will be no obvious fluctuation of speed during the whole driving process. This study used the average time of the decision stage (DT) of the data with acceleration or deceleration behavior to determine the location of action points in the behavioral data without significant speed fluctuations.

Origins and terminations of stages are shown in Table 1. The boundary between the approaching stage and the adjustment stage is the point at which the warning is issued. In this study, this point is set 150 meters from the intersection. The adjustment stage and the decision stage were counted individually for each driver depending on different action points. 


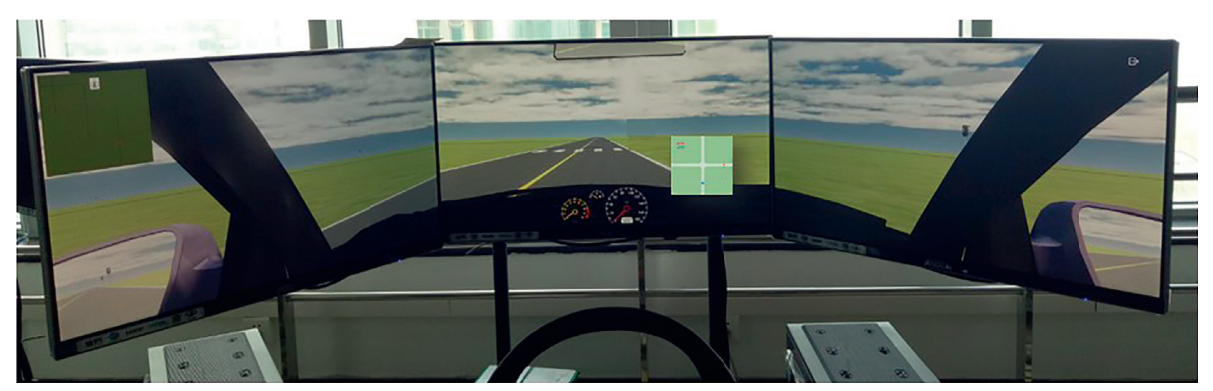

FIGURE 5: Display of the driving simulator and the warning interface.

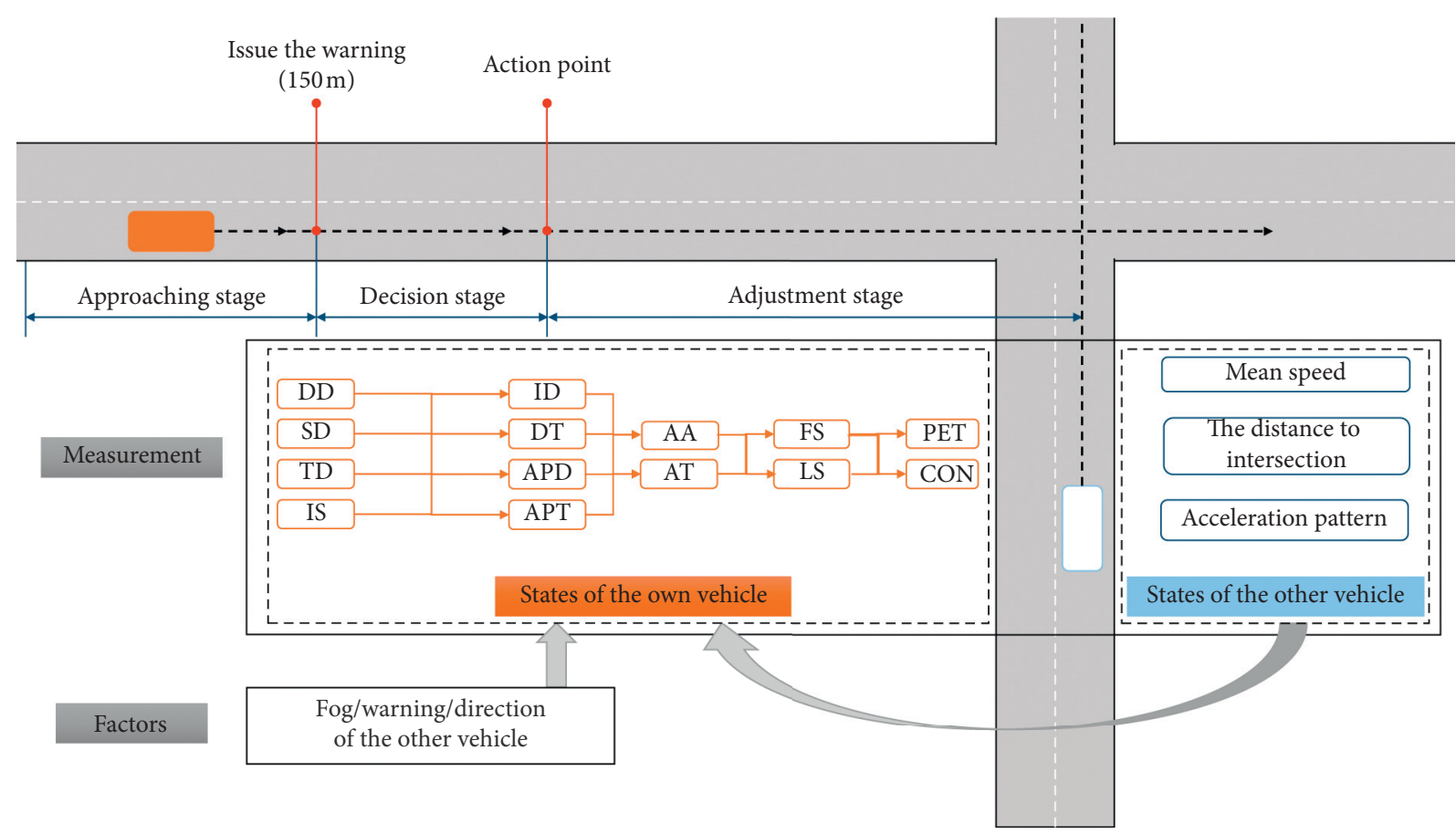

FIGURE 6: Drivers' interaction process in unsignalized intersection.

TABLE 1: Interpretation of variables.

\begin{tabular}{|c|c|c|}
\hline Stage & Definitions of behavioral measures & Notation \\
\hline \multirow{4}{*}{ Approaching stage } & Difference of two vehicles' distance at the end point of the approaching stage & DD \\
\hline & Difference of two vehicles' speed at the end point of the approaching stage & SD \\
\hline & Difference of two vehicles' TTC at the end point of the approaching stage & $\mathrm{TD}$ \\
\hline & Speed at the end point of the approaching stage & IS \\
\hline \multirow{4}{*}{ Decision stage } & Travel time in the decision stage & DT \\
\hline & Initial decision at the action point & ID \\
\hline & Distance between the action point and intersection & APD \\
\hline & Time to the intersection at the action point & APT \\
\hline \multirow{6}{*}{ Adjustment stage } & Average acceleration (deceleration) rate of the initial action. & AA \\
\hline & Duration time of the initial action & AT \\
\hline & The lowest speed of the entire adjustment stage & LS \\
\hline & Finial speed at the end point of the adjustment stage & FS \\
\hline & Postencroachment time at the end point of the adjustment stage & PET \\
\hline & Collision or not & $\mathrm{CON}$ \\
\hline
\end{tabular}


2.5.2. Behavioral Measures. Several measures of the own vehicle were adopted for describing the driving behaviors for each defined stage, as shown in Figure 6 and described in Table 1.

In the approaching stage, there were almost no driving operation actions leading to invariant speeds of the vehicles. But the difference of two vehicles' distance (DD), the difference of two vehicles' speed (SD), the difference of the two vehicles' TTC (TD), and the speed at the end of this stage (IS) were extracted as an influence variable for the following stage.

In the decision stage, drivers were aware of the potential for conflict but did not take any action. The speed of the whole stage is relatively stable until drivers made the initial decision and begun to take the initial action (acceleration or deceleration). Some of the drivers might keep a constant speed in the whole process, which was defined as "no response" conditions. Therefore, there were three categories of the initial decision. In this stage, travel time in the decision stage (DT), the initial decision at the action point (ID), the distance between the action point and the intersection (APD), and time to intersection at the action point were measured.

In the adjustment stage, drivers made the initial action, but as the speed changes, a second decision might be made. In this stage, the average acceleration (deceleration) rate of the initial action (AA), duration time of the initial action (AT), the average speed of the entire adjustment stage (AS), lowest speed of the entire adjustment stage (LS), finial speed at the endpoint of the adjustment stage (FS), and postencroachment time at the endpoint of the adjustment stage (PET) and collision or not (CON) were measured. In this study, PET was introduced as a risk assessment criterion. Surrogate safety measures included time-to-collision (TTC), time extended TTC (TET), postencroachment time (PET), and deceleration rate (DR) [37]. PET was most commonly used to identify the crossing conflicts between two road users. It referred to the time interval between two instances when the first vehicle leaves a conflict point and the second vehicle enters into it. PET had all the essential properties of surrogate safety measures. Similar to other surrogate measures, PET was estimated from observable noncrash events and indicated the resulting event of conflicts between vehicles, how closely a collision had been avoided [38].

There were two kinds of independent variables. Part of them came from external factors, including fog, warning, and direction of the other vehicle. When two vehicles crossed to an unsignalized intersection, generally speaking, vehicles on the left more likely to yield vehicles on the right [33]. It means that the direction of the other vehicle might affect driving behaviors. Therefore, the direction was treated as an independent variable. Part of them was the state of the other vehicle, including speed, the distance to intersection, and acceleration pattern of the other vehicle (acceleration, deceleration, or no response). States of the other vehicle changed dynamically with the motion of the own vehicle.

\section{Results}

3.1. Approaching Stage. In the approaching stage, no specific behavioral measures were extracted. Vehicles moved towards the intersection according to drivers' judgment. However, DD, SD, TD, and IS in the endpoint of the approaching stage (the start point of the decision stage) were extracted for subsequent analysis.

3.2. Decision Stage. In the decision stage, four behavioral measures, i.e., DT, APT, APD, and ID, were observed and analyzed. Table 2 summarizes ANOVA and the Pearson correlation results for DT, APT, and APD. It should be noted that ID is a categorical variable that is analyzed using a multinomial logit model whose results are reported in Table 3. Independent variables were warning, fog, the direction of the other vehicle, and states of the other vehicle. States of the other vehicle included the other vehicle's acceleration pattern and mean speed in the decision stage of the own vehicle and the distance between the other vehicle and intersection when the own vehicle was at the start of the decision stage.

3.2.1. Travel Time in the Decision stage (DT). DT is the reaction time of the driver. ANOVA and the Pearson correlation results of DT are shown in Table 2. The warning had an evident impact on DT $(F=116.447, P=0.000)$. Figure 7 shows the fitted mean profiles of DT with respect to warning. Mean DT of conditions without warning was $8.53 \mathrm{~s}$, which was lower than conditions with the warning $(6.41 \mathrm{~s})$. It meant that the reaction time of the driver became shorter with the help of the warning system. In the absence of the warning system, drivers needed longer reaction times to make decisions. The distance of the other vehicle showed a positive correlation (the Pearson correlation $=0.121^{* *}$, $P=0.001)$ with DT. If the distance between the other vehicle and intersection was closer, the reaction time of the driver would be shorter. The mean speed of the other vehicle and DT were negatively correlated (the Pearson correlation $\left.=-0.079^{*}, P=0.025\right)$. It meant that if the mean speed of the other vehicle was higher, reaction time would be shorter.

3.2.2. Time to the Intersection at the Action Point (APT). APT is defined as the time to the intersection at the action point. ANOVA and the Pearson correlation results of APT are illuminated in Table 2. It was found that warning $(F=114.000, p=0.000)$ significantly influenced APT. From Figure 7 , the mean of APT under the warning condition $(7.05 \mathrm{~s})$ was significantly larger than the no warning condition (5.11 s), signifying that the warning system assisted the driver to gain nearly two seconds to adjust speed. Distance (the Pearson correlation $=-0124^{*}, p=0.000$ ) of the other vehicle showed a negative correlation with APT.

3.2.3. Distance between the Action Point and Intersection $(A P D) . \mathrm{APD}$ is defined as the distance between the action 
TABle 2: ANOVA and the Pearson correlation results of DT, APT, and APD.

\begin{tabular}{|c|c|c|c|c|c|c|}
\hline \multirow{3}{*}{ Source } & \multicolumn{2}{|c|}{ DT } & \multicolumn{2}{|c|}{ APT } & \multicolumn{2}{|c|}{ APD } \\
\hline & \multicolumn{6}{|c|}{ ANOVA test } \\
\hline & F-value & Sig. & F-value & Sig. & F-value & Sig. \\
\hline Warning & 116.447 & 0.000 & 114.000 & 0.000 & 120.835 & 0.000 \\
\hline Fog & 1.818 & 0.163 & 0.354 & 0.702 & 0.640 & 0.527 \\
\hline Direction & 2.261 & 0.133 & 1.935 & 0.165 & 0.642 & 0.423 \\
\hline \multirow[t]{3}{*}{ Acceleration pattern } & 0.802 & 0.449 & 0.225 & 0.799 & 0.127 & $<0.881$ \\
\hline & \multicolumn{6}{|c|}{ Pearson correlations } \\
\hline & Value & Sig. & Value & Sig. & Value & Sig. \\
\hline Distance & $0.121^{* *}$ & 0.001 & $-0.124^{* *}$ & 0.000 & $-0.114^{* *}$ & 0.001 \\
\hline Mean speed & $-0.079^{*}$ & 0.025 & 0.048 & 0.172 & 0.056 & $<0.112$ \\
\hline
\end{tabular}

${ }^{* *}$ Correlation is significant at the 0.01 level (2-tailed). ${ }^{*}$ Correlation is significant at the 0.05 level (2-tailed).

TABle 3: Multinomial logit model results for ID.

\begin{tabular}{|c|c|c|c|c|c|c|c|}
\hline & \multicolumn{3}{|c|}{ Acceleration } & \multicolumn{3}{|c|}{ Deceleration } \\
\hline & & B & Sig. & $\operatorname{Exp}(B)$ & B & Sig. & $\operatorname{Exp}(B)$ \\
\hline Intercept & & 1.819 & 0.255 & & 6.673 & 0.000 & \\
\hline Mean speed & & -0.087 & 0.006 & 0.917 & -0.057 & 0.034 & 0.944 \\
\hline Distance & & 0.016 & 0.010 & 1.016 & -0.025 & 0.000 & 0.975 \\
\hline Warning (reference level: no warning) & Warning & 0.581 & 0.005 & 1.788 & 0.190 & 0.356 & 1.209 \\
\hline \multirow{2}{*}{ Fog (reference level: no fog) } & Light fog & -0.288 & 0.241 & 0.750 & 0.191 & 0.432 & 1.210 \\
\hline & Heavy fog & -0.499 & 0.042 & 0.607 & 0.164 & 0.496 & 1.178 \\
\hline Direction (reference level: right) & Left & -0.025 & 0.906 & 0.975 & 0.271 & 0.195 & 1.311 \\
\hline \multirow{2}{*}{ Acceleration pattern $=1$ (reference level: constant speed $)$} & Acceleration & -0.647 & 0.020 & 0.523 & -0.215 & .397 & 0.806 \\
\hline & Deceleration & 0.011 & 0.965 & 1.011 & -0.683 & .010 & 0.505 \\
\hline
\end{tabular}

point and the intersection. Table 2 lists ANOVA and the Pearson correlation results of APT. It was found that warning $(F=120.835, p=0.000)$ significantly influenced APD. As shown in Figure 7, the mean of APD under the warning condition (mean $=78.85 \mathrm{~m}$ ) was significantly larger than the no warning condition (mean $=57.49 \mathrm{~m}$ ). The difference between the two values was more than $20 \mathrm{~m}$. Distances (the Pearson correlation $=-0114^{*}, P=0.001$ ) of the other vehicle and APD were negatively correlated. According to Table 2, other factors do not significantly affect APD.

It is rational that executing the behavior of the driver at the decision stage largely depends on the warning and states of the other vehicle, irrespective of fog and direction of the other vehicle.

3.2.4. Initial Decision (ID). There are three categories of ID, namely, acceleration, deceleration, and no response. A multinomial logit model was developed to investigate the effects of factors on ID and the results are reported in Table 3. In contrast to conditions without the warning, drivers were more likely to accelerate under conditions with warning. Under the heavy fog, drivers were less likely to accelerate and more likely to keep a constant speed. When the other vehicle accelerated, drivers were less likely to choose to accelerate, and when the other vehicle decelerated, drivers were less likely to decelerate. When the average speed of the other vehicle increased, drivers were less likely to accelerate and decelerate and more likely to maintain a constant speed. When the distance of the other vehicle increased, the probability that the driver chose to accelerate increased, and the probability of decelerating decreased.

As shown in Table 4, the result of the chi-square test indicates that the acceleration pattern had a significant impact on ID $(P=0.000)$. When acceleration patterns of other vehicles were acceleration, $50 \%$ of drivers chose deceleration. When acceleration patterns of other vehicles were deceleration, $51 \%$ of drivers chose to accelerate. When acceleration patterns of other vehicles were no response, $42.1 \%$ of drivers decelerated and $37.9 \%$ of the drivers accelerated.

3.2.5. Association between $D D, T D, S D, I S$, and ID. ID is the most important result of the decision stage. DD, TD, SD, and IS were upstream variables of ID. Therefore, the classification tree was used to the association between DD, TD, SD, IS, and ID. Figure 8 illustrates the result of the classification tree that generated the following classification rules for drivers' driving decisions.

The final variables into the classification tree were DD and TD. From Node 1, when DD was less than $-3.834 \mathrm{~m}$, $58.3 \%$ of drivers accelerated, and $23.4 \%$ of drivers decelerated. Under this situation, from Node 6 and Node 7, if TD $>-0.404 \mathrm{~s}$, the probability of drivers choosing to accelerate was $40.9 \%$ and the probability of choosing to decelerate was $43.9 \%$. If $\mathrm{TD}<-0.404 \mathrm{~s}$, the probability of drivers choosing to decelerate dropped to $18.3 \%$, and the probability of choosing to accelerate and no response rose slightly. TD is a variable that reflects who can reach the intersection first 


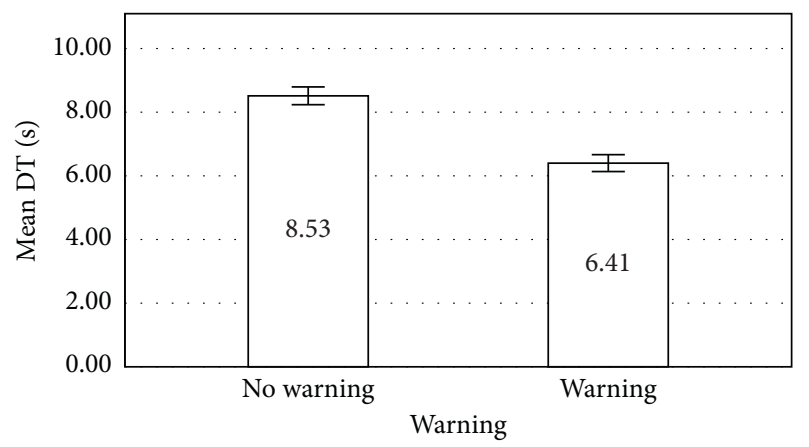

(a)

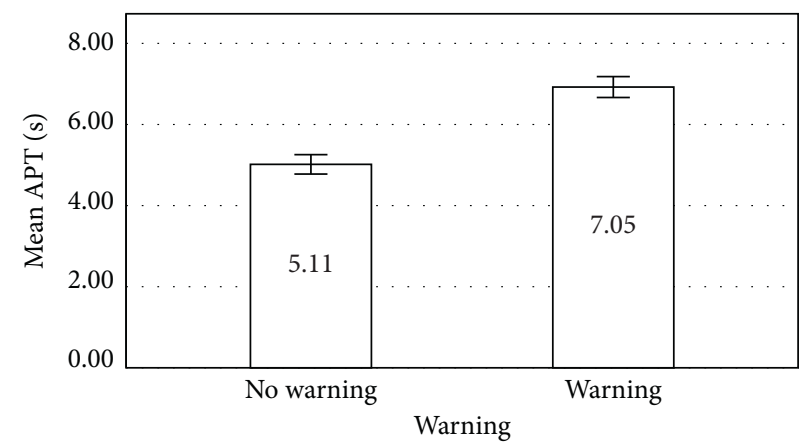

(b)

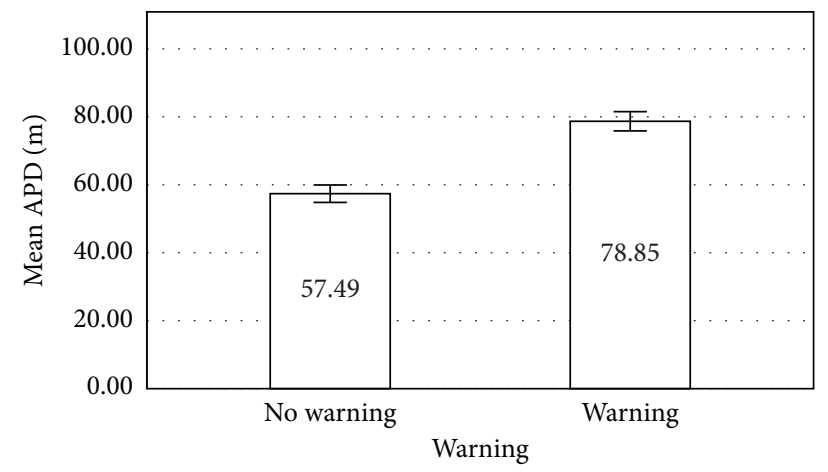

(c)

FIGURE 7: Fitted mean profiles of DT, APT, and APD with respect to different levels of factors. (a) DT. (b) APT. (c) APD.

TABle 4: Crosstab and Chi-square test result of ID.

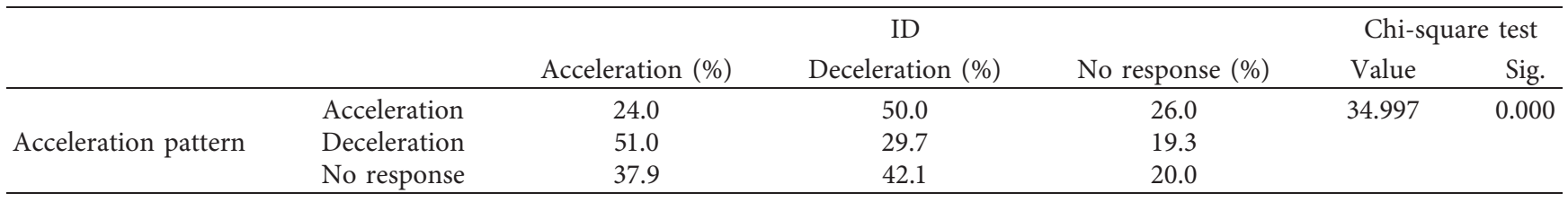

while traveling in the current state. If the driver judged that the other vehicle arrived at the intersection first, the probability that he chose to decelerate was relatively high.

From Node 1, Node 2, Node 3, and Node 4, with the increasing of $\mathrm{DD}$, the probability of drivers choosing to decelerate gradually increased, and the probability of choosing to accelerate decreased. When DD was higher than $14.483 \mathrm{~m}$, however, the probability of drivers choosing to decelerate declined. In these cases, the driver made the decision mainly by the distance from the vehicle to the intersection. As the vehicle got farther and farther from the intersection than the other vehicle, the driver was more likely to decelerate. However, when the vehicle was far enough away, the probability of a collision between the two vehicles was very small, and the probability of the driver choosing to accelerate increased.

3.3. Adjustment Stage. In the action stage, seven behavioral measures, that is, AA, AT, FS, LS, PET, and CON, were observed and analyzed. Table 5 summarizes the results of
ANOVA and the Pearson correlations for these measures and Figure 9 illustrates the fitted mean profiles with respect to different levels of factors, using the corresponding ANOVA models. Independent variables were warning, fog, the direction of the other vehicle, and states of the other vehicle. States of the other vehicle included the other vehicle's acceleration pattern and mean speed in the adjustment stage of its vehicle and distance between the other vehicle and intersection when the own vehicle was at the action point. CON is a categorical variable with two values: collision (1) and noncollision (0). A binary logit model was used to analyze CON, as listed in Table 6.

3.3.1. Average Acceleration (deceleration) Rate at Adjustment Stage $(A A)$. AA reflects the stability of the vehicle's speed during initial action. From Table 5, AA significantly depended on warning $(p=0.003)$ and fog $(p=0.008)$. As illustrated in Figure 8, the average of AA under conditions with the warning was $0.03 \mathrm{~m} / \mathrm{s}^{2}$, while under conditions without warning it was $-0.58 \mathrm{~m} / \mathrm{s}^{2}$. It verified that, with the 


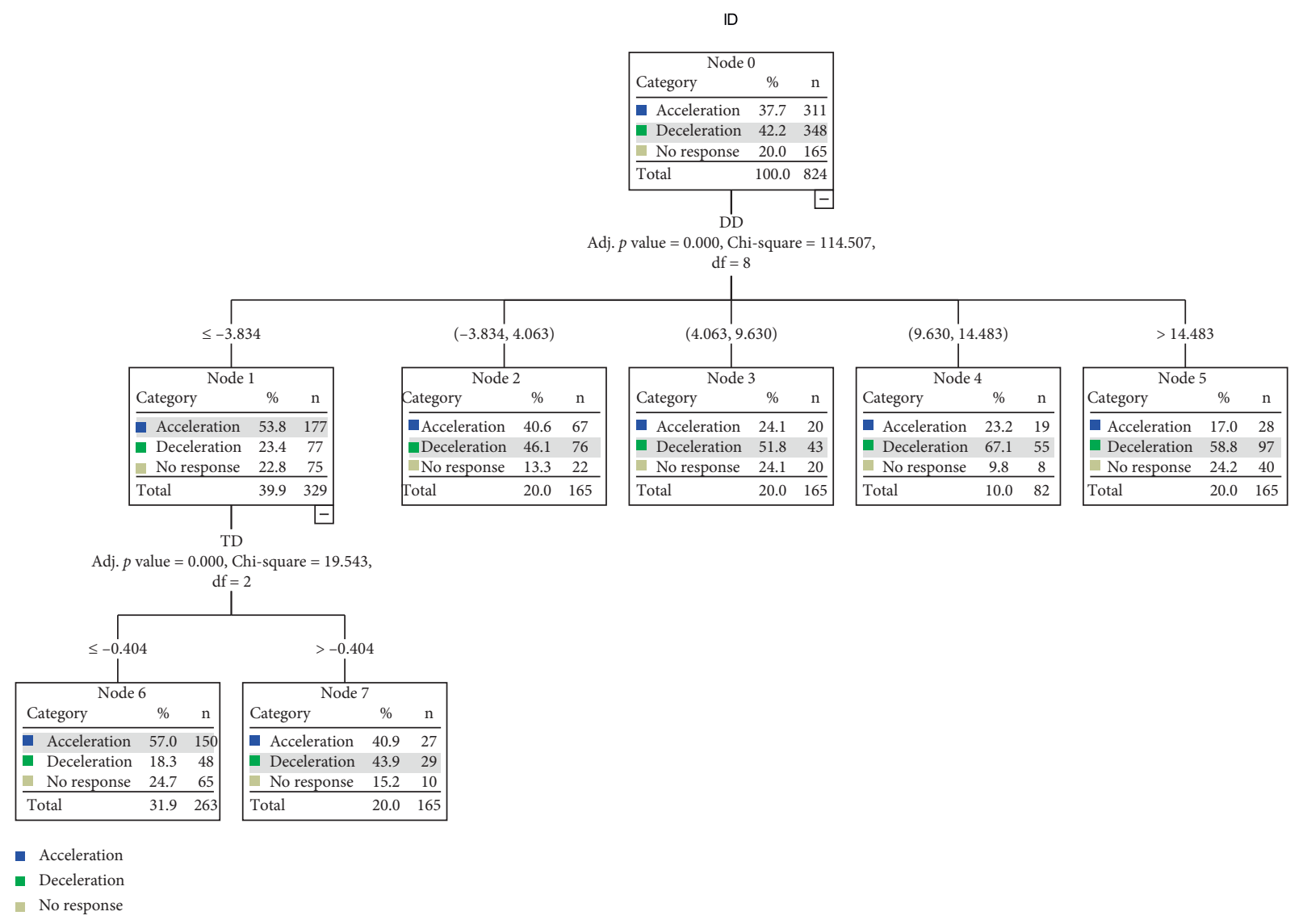

Figure 8: Classification tree result of ID.

TABle 5: ANOVA and the Pearson correlation results of AA, AT, LS, FS, and PET.

\begin{tabular}{|c|c|c|c|c|c|c|c|c|c|c|}
\hline \multirow{3}{*}{ Source } & \multicolumn{2}{|c|}{ AA } & \multicolumn{2}{|c|}{ At } & \multicolumn{2}{|c|}{ LS } & \multicolumn{2}{|c|}{ FS } & \multicolumn{2}{|c|}{ PET } \\
\hline & \multicolumn{10}{|c|}{ ANOVA } \\
\hline & F-value & Sig. & F-value & Sig. & F-value & Sig. & F-value & Sig. & F-value & Sig. \\
\hline Warning & 8.984 & 0.003 & 62.880 & 0.000 & 2.041 & 0.154 & 25.436 & 0.000 & 42.944 & 0.000 \\
\hline Fog & 4.898 & 0.008 & 2.320 & 0.099 & 8.262 & 0.000 & 8.326 & 0.000 & 4.774 & 0.009 \\
\hline Direction & 1.154 & 0.283 & 7.280 & 0.007 & 0.034 & 0.854 & 0.953 & 0.329 & 0.000 & 0.995 \\
\hline \multirow[t]{3}{*}{ Acceleration pattern } & 11.300 & 0.000 & 30.839 & 0.000 & 17.839 & 0.000 & 3.231 & 0.040 & 1.586 & 0.205 \\
\hline & \multicolumn{10}{|c|}{ Pearson correlations } \\
\hline & Value & Sig. & Value & Sig. & Value & Sig. & Value & Sig. & Value & Sig. \\
\hline Distance & $0.319^{* *}$ & 0.000 & $0.601^{* *}$ & 0.000 & $0.217^{* *}$ & 0.000 & $0.307^{* *}$ & 0.000 & $0.159^{* *}$ & 0.000 \\
\hline Mean speed & $-0.160^{* *}$ & 0.000 & $0.069^{*}$ & 0.047 & -0.032 & 0.356 & $-0.087^{*}$ & 0.013 & $-0.123^{* *}$ & 0.001 \\
\hline
\end{tabular}

${ }^{* *}$ Correlation is significant at the 0.01 level (2-tailed). ${ }^{*}$ Correlation is significant at the 0.05 level (2-tailed).

help of the warning system, the vehicle's speed would change more smoothly. Compared with no fog $\left(0.16 \mathrm{~m} / \mathrm{s}^{2}\right)$ and heavy fog $\left(0.44 \mathrm{~m} / \mathrm{s}^{2}\right)$ conditions, speed change processes of vehicles were most unstable under light fog conditions $\left(-0.58 \mathrm{~m} / \mathrm{s}^{2}\right)$. The acceleration pattern of the other vehicle also significantly affected AA. When the acceleration pattern of the other vehicle was acceleration, the own vehicle's speed changed more sharply with a mean value of $-0.77 \mathrm{~m} / \mathrm{s}^{2}$. As shown in Figure 10, when the acceleration pattern of the other vehicle was deceleration, the mean value was $0.26 \mathrm{~m} / \mathrm{s}^{2}$, which represented a more stable speed adjustment process.
Distance (the Pearson correlation $=0.319^{* *}, P=0.000$ ) and mean speed (the Pearson correlation $=-0.160^{* *}, P=0.000$ ) of the other vehicle, also significantly correlated with AA. According to Table 5, other factors do not significantly affect AA.

3.3.2. Duration Time of the Initial Action (AT). AT was defined as the duration time of the initial action. All factors significantly influenced AT except for fog. From Figure 8, compared with cases without warning (mean $=5.55 \mathrm{~s}$ ), the 

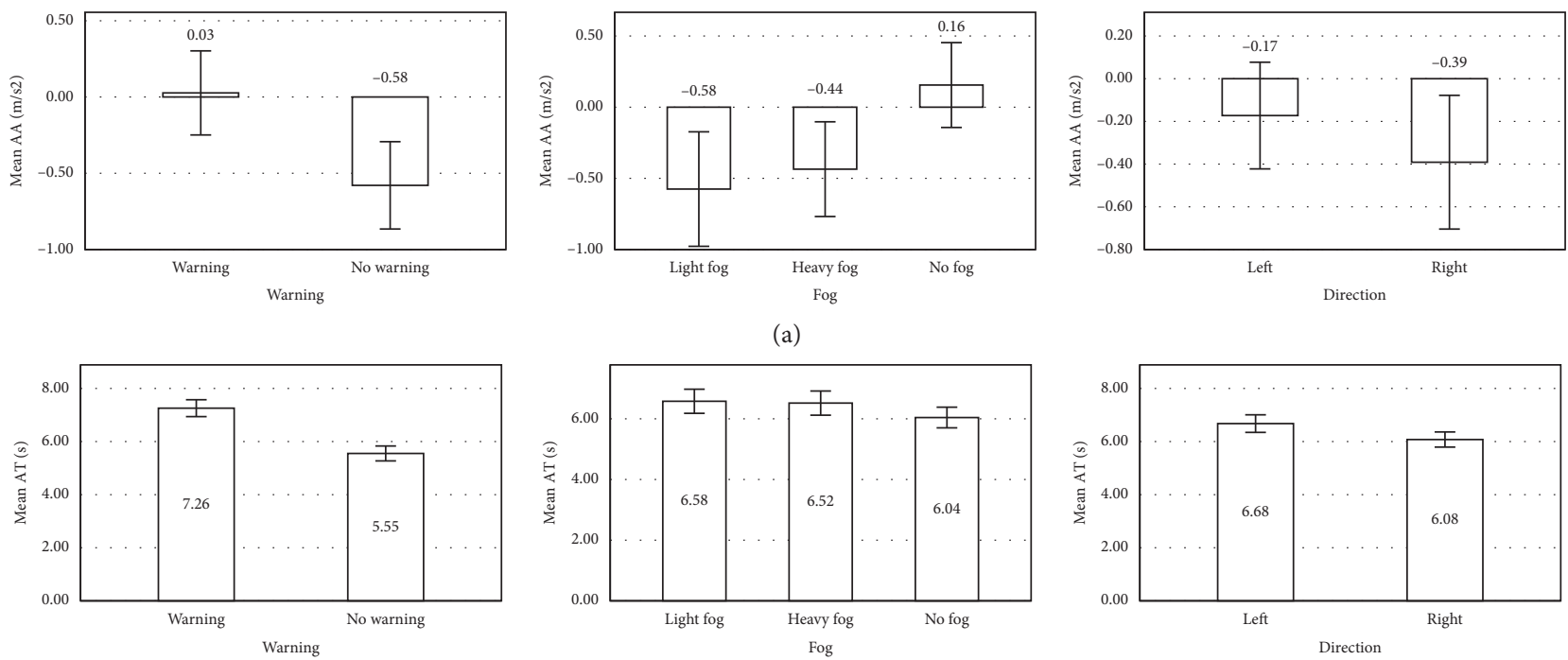

(a)
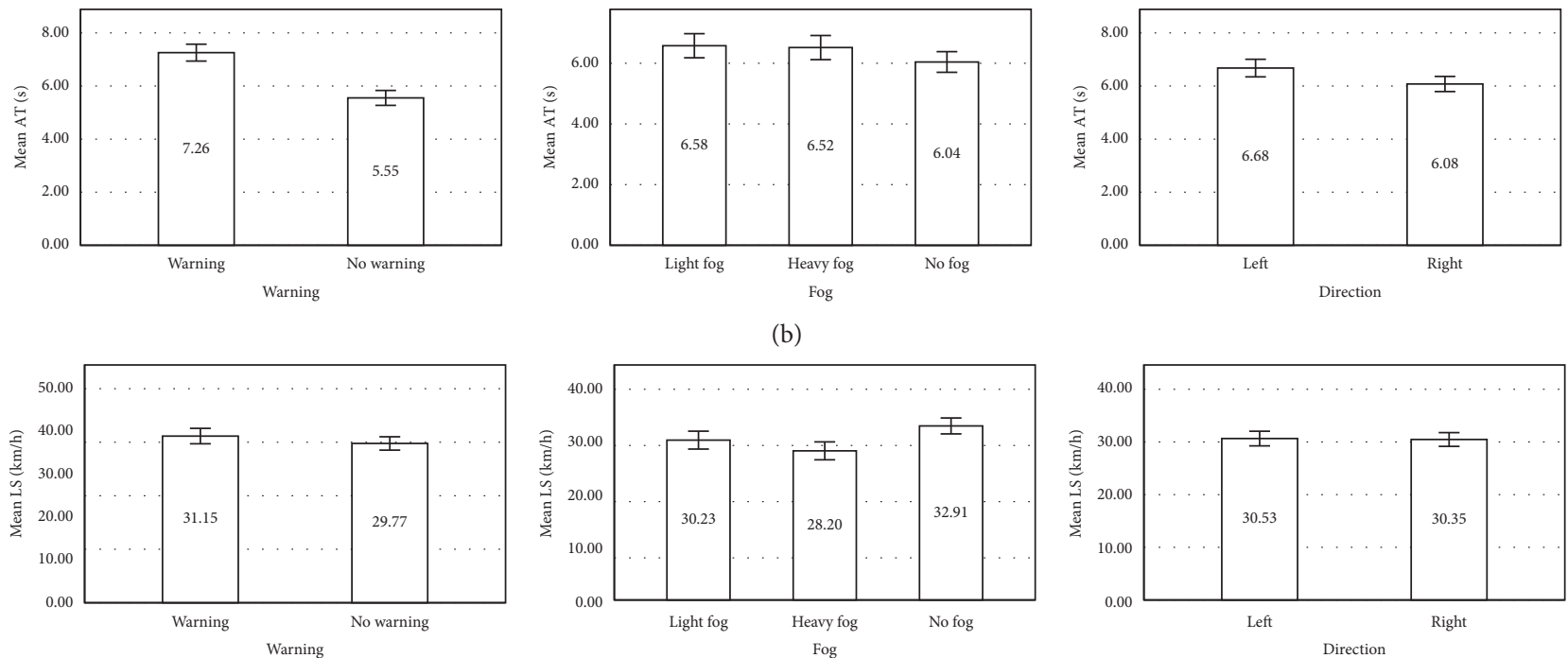

(c)
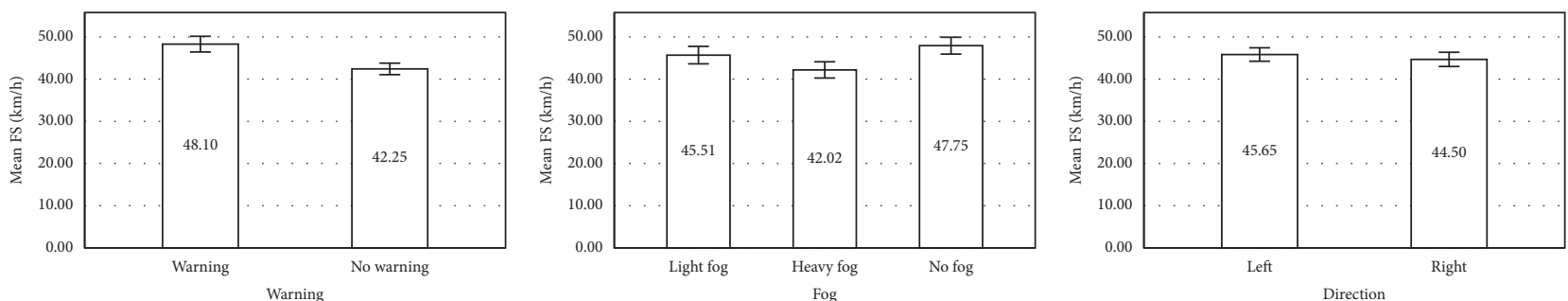

(d)
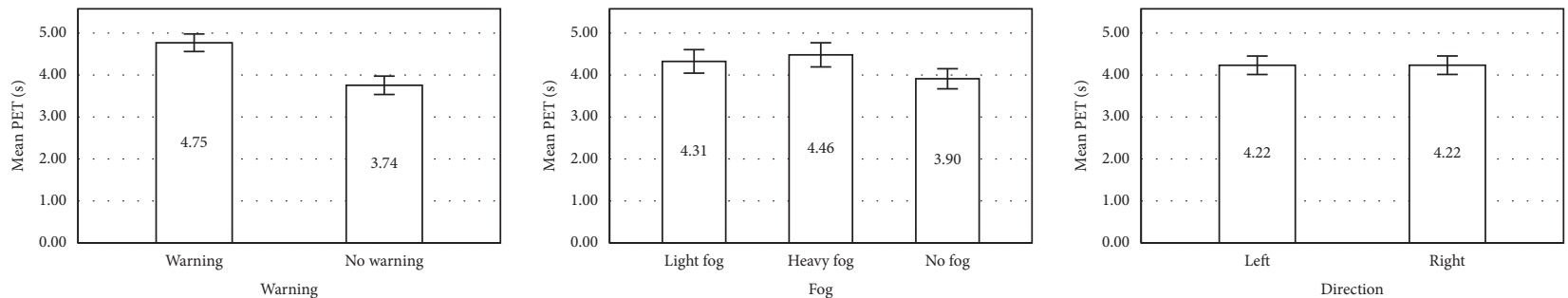

(e)

Figure 9: Fitted mean profiles of AA, AT, FS, LS, and PET with respect to different levels of factors. (a) AA; (b) AT; (c) LS; (d) FS; and (e) PET.

duration time of the initial action of the case with the warning (mean $=7.26 \mathrm{~s}$ ) was longer. When the other vehicle came from the left, the average AT of the own vehicle was $6.68 \mathrm{~s}$. By contrast, when it came from the right, the average AT became shorter (mean $=6.08 \mathrm{~s})$. States of the other vehicle also had impacts on the behavior of the own vehicle. From Figure 11, when the acceleration pattern of the other vehicle was deceleration, the average AT of the own vehicle was $5.42 \mathrm{~s}$, which was shortest compared with the average AT when it was deceleration or no response. Distance (the Pearson correlation $=0.601^{* *}, P=0.000$ ) and mean speed (the Pearson correlation $=0.069^{*}$, $P=0.047$ ) of the other vehicle and AT were positively correlated. 
TABLE 6: Binary logit model results for CON.

\begin{tabular}{|c|c|c|c|}
\hline & $\mathrm{B}$ & Sig. & $\operatorname{Exp}(B)$ \\
\hline Warning (reference level: no warning) & -2.695 & 0.000 & 0.068 \\
\hline Fog (reference level: no fog) & & 0.618 & \\
\hline Light fog & -0.442 & 0.341 & 0.642 \\
\hline Heavy fog & -0.283 & 0.537 & 0.753 \\
\hline Direction: Left (reference level: right) & 0.193 & 0.621 & 1.213 \\
\hline Speed & 0.022 & 0.199 & 1.022 \\
\hline Acceleration pattern (reference level: no response) & & 0.000 & \\
\hline Acceleration & -0.869 & 0.241 & 0.419 \\
\hline Deceleration & 1.359 & 0.019 & 3.893 \\
\hline Distance & -0.016 & 0.022 & 0.984 \\
\hline Constant & -3.032 & 0.004 & 0.048 \\
\hline
\end{tabular}

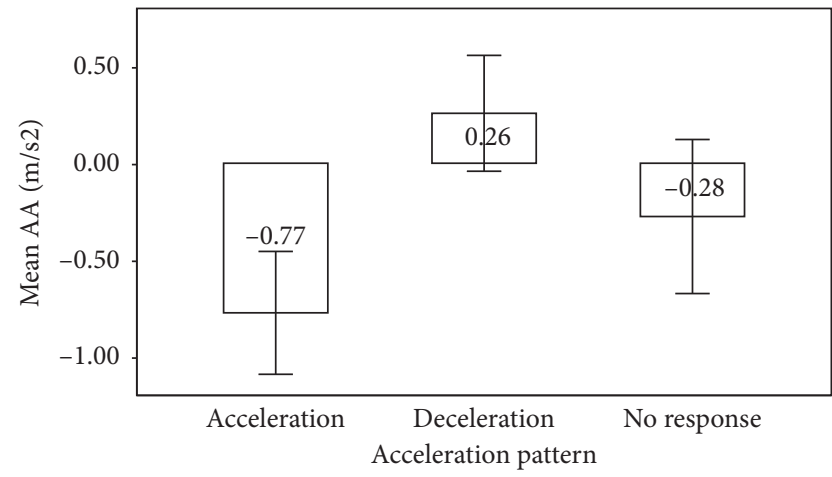

FIGURE 10: Fitted mean profiles of AA with respect to acceleration pattern.

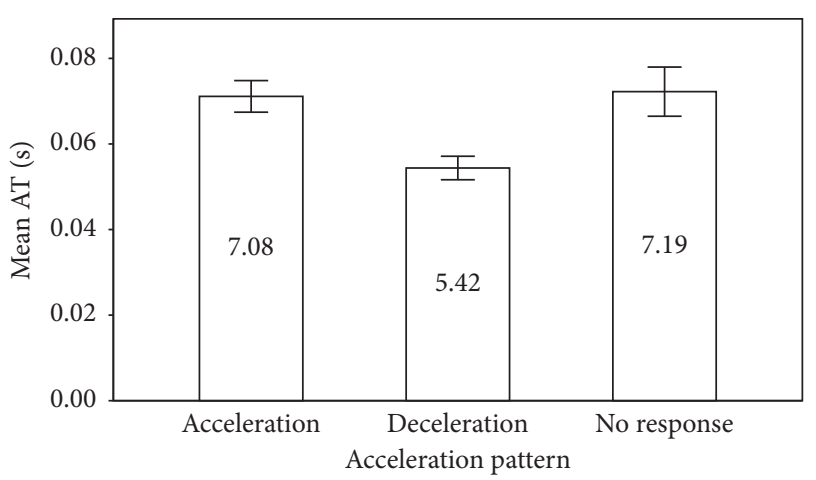

FIGURE 11: Fitted mean profiles of AT with respect to acceleration pattern.

3.3.3. The Lowest Speed of the Entire Adjustment Stage (LS). LS is the minimum speed of the adjustment stage, which reflects the driving safety in this stage to some extent. As illustrated in Table 5, fog and direction had significant effects on LS. From Figure 9, in heavy fog conditions, average LS was $28.20 \mathrm{~km} / \mathrm{h}$, which was lower than the no fog condition and the light fog condition. As shown in Figure 12, when the acceleration pattern of the other vehicle was deceleration, average LS of the own vehicle was the highest $($ mean $=33.62 \mathrm{~km} / \mathrm{h})$. The distance of the other vehicle was positively correlated with LS (the Pearson correlation $\left.=0.217^{* *}, P=0.000\right)$.

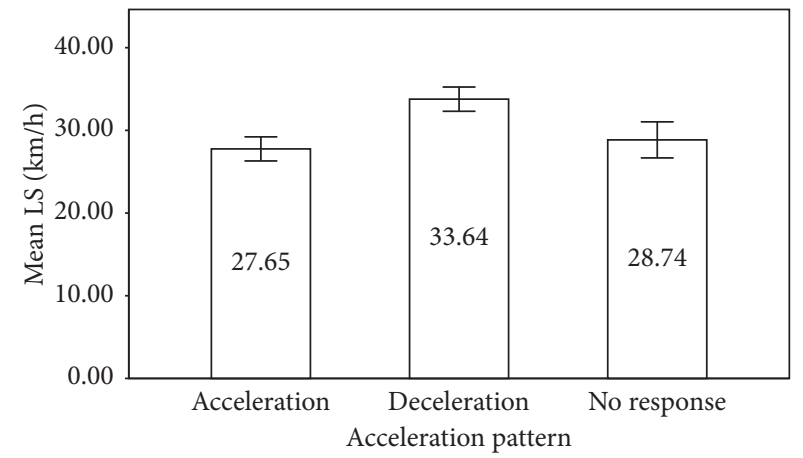

FIgURE 12: Fitted mean profiles of LS with respect to acceleration pattern.

3.3.4. Finial Speed at the Endpoint of the Adjustment Stage (FS). FS is the final speed of the vehicle as it passes the intersection. From Table 5, warning and fog significantly influenced FS. As illustrated in Figure 9, in the case of the warning effect, the average FS was $48.1 \mathrm{~km} / \mathrm{h}$, which was higher than the case without the warning effect (mean $=42.25 \mathrm{~km} / \mathrm{h}$ ). The average of FS was the lowest in the heavy fog condition (mean $=42.02 \mathrm{~km} / \mathrm{h}$ ). Distance (the Pearson correlation $=0.307^{* *}, P=0.000$ ) and FS were positively correlated, and the mean speed (the Pearson correlation $=-0.087^{*}, P=0.013$ ) of the other vehicle and FS were negatively correlated. It meant that if the mean speed of the other vehicle got higher, the final speed of the own vehicle got lower.

3.3.5. Postencroachment Time of the Two Vehicles at the End of Action Point (PET). PET (postencroachment time) reflects the chance of conflict between the two vehicles. Among those factors, warning and fog a significant had impact on PET. From Figure 9, the average value of PET varied a lot with $($ mean $=4.75 \mathrm{~s})$ and without $($ mean $=3.73 \mathrm{~s})$ the warning. Apparently, the probability of a collision was higher without warning. But contrary to common sense, collisions were least likely in heavy fog, where PET was $4.46 \mathrm{~s}$. Distance (the Pearson correlation $=0.159^{* *}$, $P=0.000)$ and PET were positively correlated, and the mean speed (the Pearson correlation $=-0.123^{* *}, P=0.001$ ) of the other vehicle was negatively correlated with PET. The farther 
the distance between the other vehicle and the intersection when the own vehicle was at the action point, or the lower the average speed of the other vehicle, the safer it was for the drivers.

3.3.6. Collision or Not (CON). From Table 6, the warning and acceleration pattern and distance of the other vehicle had a significant impact on CON. Compared with conditions without warning, collisions were less likely when there were warnings. Collisions were more likely when the other vehicle accelerated and the smaller the distance between the other vehicle and the intersection is, the more likely an accident would occur.

\subsection{Association between the Key Variables during the Whole} Process. PET is the result of the whole process. For drivers, the higher the PET, the safer the crossing. As illustrated in Figure 13, the classification tree was used to analyze the association between the key variables during the whole process and PET. The final variables into the classification tree were APT and LS. It meant that whether the driver could safely pass the intersection was determined by the time to the intersection at the action point of the vehicle and the minimum speed of the whole process.

If APT was lower than $2.579 \mathrm{~s}$, the mean of PET was $2.187 \mathrm{~s}$ (Node 1). If APT was higher than $2.579 \mathrm{~s}$, the mean was $4.439 \mathrm{~s}$ (Node 2). Under this situation, from Node 3, Node 4, and Node 5, as LS increased, PET showed a decreasing trend. When LS was greater than $19.556 \mathrm{~km} / \mathrm{h}$, the mean of PET was $4.177 \mathrm{~s}$ (Node 5). At this point, if APT > $5.276 \mathrm{~s}$, the mean of PET was $4.326 \mathrm{~s}$, which was higher than the situation when APT was lower than $5.367 \mathrm{~s}$.

\section{Discussion}

By using multiuser driving simulator, this study investigated drivers' collision avoidance performance at unsignalized intersection with consideration of the intervention of ICWS and fog conditions. Obviously, ICWS could really improve driving safety under fog conditions and the results have been measurable and significant.

Previous studies on driving behavior in fog have been carried out using different kinds of driving simulators. However, the experimental results indicated consistent findings regarding driving behavior. Reduced visibility in fog increased the risk of collision to some extent, and most drivers were likely to perform safety-related adaptations in order to give themselves more time to react to hazards [39]. Some experiments indicated the driver could maintain a good lane-keeping ability, but the visibility was restricted and the driver could not avoid road danger effectively [8]. The findings of this study reiterated the general consensus in the driving literature. Acceleration behaviors decreased with reduced visibility, suggesting that drivers were more cautious. Despite that, the driving risk did not decrease, causing the driver's reaction to be slower than when there was no fog. The results indicated that although drivers tended to perform more cautiously in fog, the driving risk was still increased due to the difficulty in perceiving the environment [40].

However, what was different from the past was that the speed of the whole process changed more sharply in light fog conditions than heavy fog conditions. As mentioned above, there were many ways that drivers might compensate for fog weather, including avoiding certain situations and performing extra eye or head movements, and one simple way to compensate was by slowing down $[41,42]$. Our results indicated that drivers were more cautious in heavy fog than light fog and no fog conditions because the minimum speed in the heavy fog was the lowest compared with other conditions. From Figure 12, the minimum speed had a significant impact on PET. It meant that the minimum speed to some extent determined whether or not a collision occurred. That is why in this experiment, drivers were less likely to have an accident in heavy fog.

Previous surveys [24] have illustrated that the collision avoidance systems were effective in enhancing drivers' performances and successfully assisting drivers to avoid potential accidents as indicated by lower collision rates. It was found that earlier warning conditions could provide drivers more time and distance to be ready to respond accordingly with the most appropriate actions [43]. A similar benefit of this ICWS was achieved in this study. The ICWS designed in this paper expanded the limited vision of drivers to some degree. Drivers can more accurately judge how to avoid conflicts through the information provided by the warning interface, that is why drivers had different behavioral preferences under different warning conditions. Acceleration behavior was more frequent in the warning condition, which was an active way to avoid collision rather than meaning radical or dangerous. Besides, under the warning condition, drivers made decisions earlier, and the speed changing process was more smooth. The most significant aspect was that the warning system immensely reduced the risk of driving, judging from the mean profile of PET under different warning conditions. These findings confirmed previous research results on the warning system [44-47].

Few studies have analyzed the interactive decisionmaking mechanism due to defects in real vehicle data and single driving simulator. This experiment carried out by MDS recorded the interactive decision-making process of two drivers in detail. In the process of vehicles passing through the intersection, for each individual driver, they mainly used DD (distance difference) and TD (time difference) to make decisions, as analyzed in Figure 8. The effect of states of the other vehicle on the own vehicle was significant. When the other vehicle accelerated, the driver was more likely to decelerate. In contrast, when the other vehicle decelerated, the driver was more likely to accelerate. The speed and distance to the intersection of the other vehicle also significantly influenced the driver's behavior. At the same time, these also determined whether the driver could safely cross the intersection. 


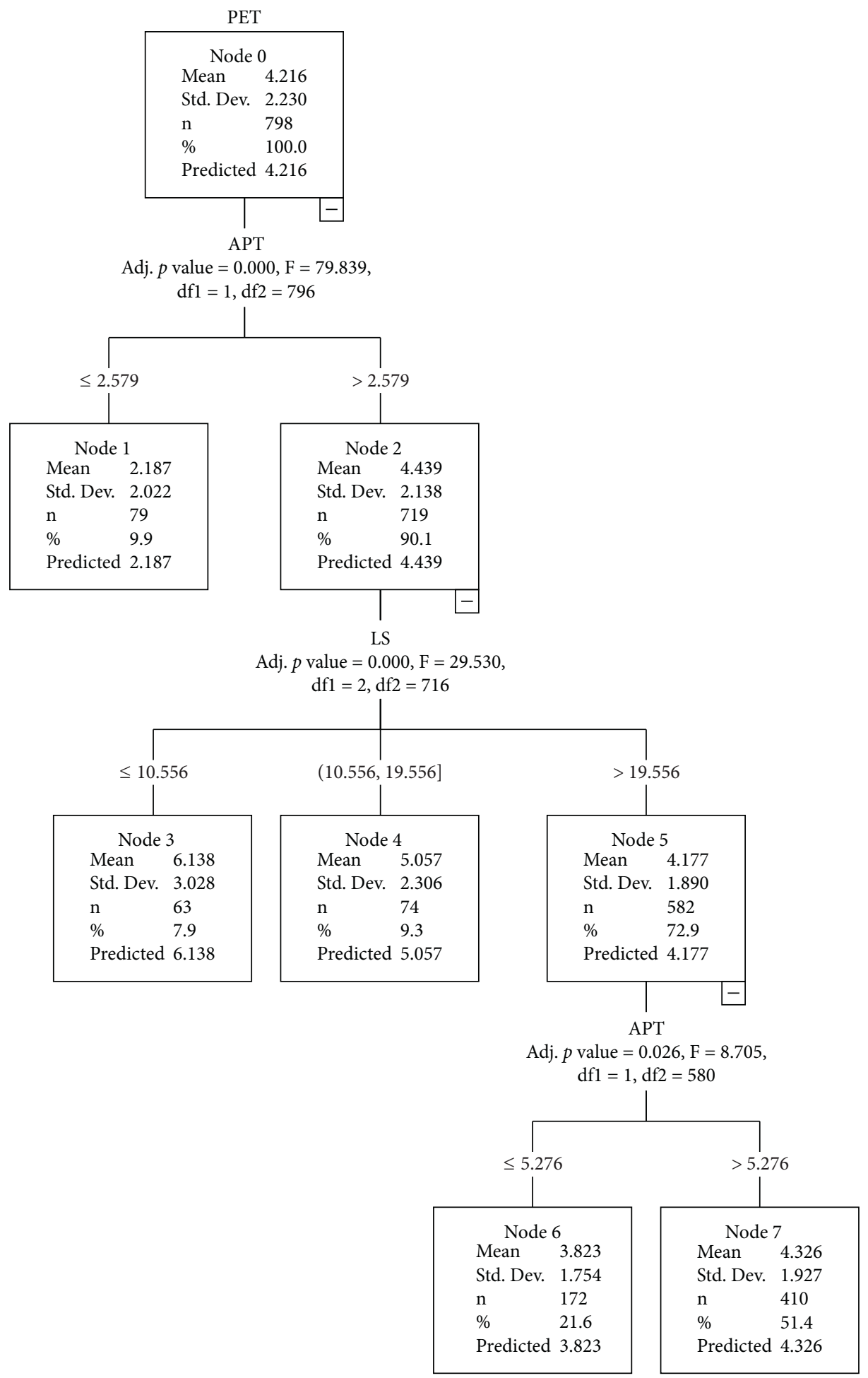

Figure 13: Classification tree result of PET.

\section{Conclusions}

The limitation of this study is that there was always the risk that subjects might not interpret the experimental task as they would in real life. In other words, their behavior might not be completely realistic under simulated driving conditions [7]. Although the simulated fog was similar to real fog, it was not exactly the same. Furthermore, the methods of using relative variables of the drivers to represent the interaction relationship and the left and right vehicles were analyzed separately simplifying the cooperative decisionmaking mechanism, which requires further study. The warning conditions of this study were designed for the visual intersection collision warning system only, in which 
conclusions should be carefully applied for addressing other collision warning scenarios.

In summary, this study has illustrated the effects of the visual collision avoidance warning system on drivers' behavior in no fog, light fog, and heavy fog scenarios based on MDS. The results indicated that the fog and warning conditions, even direction, had a significant influence on driving behavior. With the assistance of ICMS, drivers could obtain more detailed and accurate environmental information; therefore, drivers' decisions were more reasonable and efficient. The interactive decision process of the two vehicles was explained amply. The findings of this study would be useful for improving the effectiveness of the visual intersection collision warning system and interactive driving behavior study.

\section{Data Availability}

The behavioral data used to support the findings of this study are restricted by the independent ethics committee (IRB) in order to protect the privacy of participants.

\section{Conflicts of Interest}

The authors declare that there are no conflicts of interest regarding the publication of this paper.

\section{Acknowledgments}

This work was financially supported by National Natural Science Foundation of China (71771014 and 71621001)

\section{References}

[1] Z. Wu, J. Yang, and L. Huang, "Study on the collision avoidance strategy at unsignalized intersection based on PreScan simulation," Procedia - Social and Behavioral Sciences, vol. 96, pp. 1315-1321, 2013.

[2] M. Liu, G. Lu, Y. Wang, and Z. Zhang, "Analyzing drivers' crossing decisions at unsignalized intersections in China," Transportation Research Part F: Traffic Psychology and Behaviour, vol. 24, pp. 244-255, 2014.

[3] X. Yan, X. Li, Y. Liu, and J. Zhao, "Effects of foggy conditions on drivers' speed control behaviors at different risk levels," Safety Science, vol. 68, pp. 275-287, 2014.

[4] L. F. Musk, "The local fog hazard as a factor in planning new roads and motorways," Environmental Education and Information, vol. 2, pp. 119-129, 1982.

[5] Y. Wu, M. Abdel-Aty, J. Park, and R. M. Selby, "Effects of realtime warning systems on driving under fog conditions using an empirically supported speed choice modeling framework," Transportation Research Part C: Emerging Technologies, vol. 86, pp. 97-110, 2018.

[6] M. Abdel-Aty, A.-A. Ekram, H. Huang, and K. Choi, "A study on crashes related to visibility obstruction due to fog and smoke," Accident Analysis \& Prevention, vol. 43, no. 5, pp. 1730-1737, 2011.

[7] A. S. Mueller and L. M. Trick, "Driving in fog: the effects of driving experience and visibility on speed compensation and hazard avoidance," Accident Analysis \& Prevention, vol. 48, pp. 472-479, 2012.
[8] X. Chen, J. Tian, and X. Xu, "Driving Performance Research in Foggy Conditions Based on Driving Simulator," in Theory, Methodology, Tools and Applications for Modeling and Simulation of Complex Systems, L. Zhang, X. Song, and Y. Wu, Eds., Springer Singapore, vol. 645, pp. 477-483, Singapore, 2016.

[9] K. Mollu, M. Biesbrouck, L. Van Broeckhoven et al., "Priority rule signalization under two visibility conditions: driving simulator study on speed and lateral position," Transportation Research Part F: Traffic Psychology and Behaviour, vol. 58, pp. 156-166, 2018.

[10] N. Tsukada and M. Fukushima, "An empirical study of measures for preventing crossing path collisions at unsignalized intersections-development of driving safety support systems using infrastructure-vehicle communication," International Journal of Intelligent Transportation Systems Research, vol. 9, no. 2, pp. 82-92, 2011.

[11] J. Wang, X. Xue, R. Chai, and N. Cao, "A temporal-spatial collision warning method at non-signalized intersection," Procedia Engineering, vol. 137, pp. 827-835, 2016.

[12] Y. Liu, O. Ozguner, and E. Ekici, "Performance evaluation of intersection warning system using a vehicle traffic and wireless simulator," IEEE Proceedings. Intelligent Vehicles Symposium, vol. 2005, Article ID 1505097, 176 pages, 2005.

[13] C. Lee, B. Hellinga, and F. Saccomanno, "Real-time crash prediction model for application to crash prevention in freeway traffic," Transportation Research Record: Journal of the Transportation Research Board, vol. 1840, no. 1, pp. 67-77, 2003.

[14] F. D. Salim, S. W. Loke, A. Rakotonirainy, B. Srinivasan, and S. Krishnaswamy, "Collision Pattern Modeling and Real-Time Collision Detection at Road Intersections," in Proceedings of the 2007 IEEE Intelligent Transportation Systems Conference, pp. 161-166, Bellevue, WA, USA, September 2007.

[15] H. Fritz, A. Gern, H. Schiemenz, and C. Bonnet, "CHAUFFEUR Assistant: a driver assistance system for commercial vehicles based on fusion of advanced ACC and lane keeping," IEEE Intelligent Vehicles Symposium, vol. 2004, Article ID 1336433, 500 pages, 2004.

[16] A. Buchenscheit, F. Schaub, F. Kargl, and M. Weber, "A VANET-based emergency vehicle warning system," in Proceedings of the 2009 IEEE Vehicular Networking Conference (VNC), pp. 1-8, Tokyo, Japan, October 2009.

[17] C. Passmann, C. Brenzel, and R. Meschenmoser, "Wireless vehicle to vehicle warning system," in Proceedings of the SAE Technical Paper Series, SAE International, Warrendale, PA, March 2000, SAE Technical Paper 2000-01-1307.

[18] S.-H. Chang, C.-Y. Lin, C.-C. Hsu, C.-P. Fung, and J.-R. Hwang, "The effect of a collision warning system on the driving performance of young drivers at intersections," Transportation Research Part F: Traffic Psychology and Behaviour, vol. 12, no. 5, pp. 371-380, 2009.

[19] F. Bella and M. Silvestri, "Effects of directional auditory and visual warnings at intersections on reaction times and speed reduction times," Transportation Research Part F: Traffic Psychology and Behaviour, vol. 51, pp. 88-102, 2017.

[20] E. Haas and J. Edworthy, An Introduction to Auditory Warnings and Alarms, pp. 189-198, Handbook of warnings, Boca Raton, FL, USA, 2006.

[21] J. Werneke and M. Vollrath, "How to present collision warnings at intersections?-A comparison of different approaches," Accident Analysis \& Prevention, vol. 52, pp. 91-99, 2013. 
[22] A. Dogan et al., "Evaluation of intersection collision warning system using an inter-vehicle communication simulator," in Proceedings. The 7th International IEEE Conference On Intelligent Transportation Systems, IEEE Cat. No.04TH8749), pp. 1103-1108, Washington, DC, USA, October 2004.

[23] J. K. Caird, S. L. Chisholm, and J. Lockhart, "Do in-vehicle advanced signs enhance older and younger drivers' intersection performance? Driving simulation and eye movement results," International Journal of Human-Computer Studies, vol. 66, no. 3, pp. 132-144, 2008.

[24] X. Yan, Y. Zhang, and L. Ma, "The influence of in-vehicle speech warning timing on drivers' collision avoidance performance at signalized intersections," Transportation Research Part C: Emerging Technologies, vol. 51, pp. 231-242, 2015.

[25] K. Tanaka, S. Fukushima, K. Morita, M. Sekine, and K. Tanaka, "Warning system for avoiding collisions at intersections," IFAC Proceedings Volumes, vol. 43, no. 13, pp. 204-209, 2010.

[26] F. Schwarz and W. Fastenmeier, "Visual advisory warnings about hidden dangers: effects of specific symbols and spatial referencing on necessary and unnecessary warnings," Applied Ergonomics, vol. 72, pp. 25-36, 2018.

[27] Y. Zhang, X. Yan, X. Li, and Q. Xue, "Drivers' eye movements as a function of collision avoidance warning conditions in red light running scenarios," Accident Analysis \& Prevention, vol. 96, pp. 185-197, 2016.

[28] X. Yan, J. Wang, and J. Wu, "Effect of in-vehicle audio warning system on driver's speed control performance in transition zones from rural areas to urban areas," International Journal of Environmental Research and Public Health, vol. 13, no. 7, p. 634, 2016.

[29] D. Marshall, J. Lee, and R. Austria, "Alerts for In-Vehicle Information Systems: Annoyance, Urgency, and Appropriateness," Human Factors, vol. 49, pp. 145-157, 2007.

[30] F. Schwarz and W. Fastenmeier, "Augmented reality warnings in vehicles: effects of modality and specificity on effectiveness," Accident Analysis \& Prevention, vol. 101, pp. 55-66, 2017.

[31] Y. Cao, S. Castronovo, A. Mahr, and C. Müller, "On timing and modality choice with local danger warnings for drivers," in Proceedings Of the 1st International Conference On Automotive User Interfaces And Interactive Vehicular Applications - AutomotiveUI '09, p. 75, Essen, Germany, September 2009.

[32] J. Park and W. Park, "Functional requirements of automotive head-up displays: a systematic review of literature from 1994 to present," Applied Ergonomics, vol. 76, pp. 130-146, 2019.

[33] M. Houtenbos, J. C. F. de Winter, A. R. Hale, P. A. Wieringa, and M. P. Hagenzieker, "Concurrent audio-visual feedback for supporting drivers at intersections: a study using two linked driving simulators," Applied Ergonomics, vol. 60, pp. 30-42, 2017.

[34] Y. Zhang, X. Yan, X. Li, and J. Wu, "Changes of drivers' visual performances when approaching a signalized intersection under different collision avoidance warning conditions," Transportation Research Part F: Traffic Psychology and Behaviour, vol. 65, p. 584, 2019.

[35] C. Ho and C. Spence, "Using peripersonal warning signals to orient a driver's gaze," Human Factors: The Journal of the Human Factors and Ergonomics Society, vol. 51, no. 4, pp. 539-556, 2009.

[36] L. Li, S. You, C. Yang, B. Yan, J. Song, and Z. Chen, "Driving-behavior-aware stochastic model predictive control for plug-in hybrid electric buses," Applied Energy, vol. 162, pp. 868-879, 2016.
[37] A. Pirdavani, T. Brijs, T. Bellemans, and G. Wets, "Evaluation of traffic safety at un-signalized intersections using microsimulation: a utilization of proximal safety indicators," vol. 9, 2010.

[38] M. Paul, "Safety assessment at unsignalized intersections using post-encroachment time's threshold-a sustainable solution for developing countries," in Advances in Transportation Engineering, S. Pulugurtha, I. Ghosh, and S. Biswas, Eds., vol. 34, pp. 117-131, Springer Singapore, Singapore, 2019.

[39] R. Ni, J. Kang, and G. Andersen, "Age-related declines in car following performance under simulated fog conditions," Accident; Analysis and Prevention, vol. 42, pp. 818-826, 2010.

[40] X. Li, X. Yan, and S. C. Wong, "Effects of fog, driver experience and gender on driving behavior on S-curved road segments," Accident Analysis \& Prevention, vol. 77, pp. 91-104, 2015.

[41] L. M. Trick, R. Toxopeus, and D. Wilson, "The effects of visibility conditions, traffic density, and navigational challenge on speed compensation and driving performance in older adults," Accident Analysis \& Prevention, vol. 42, no. 6, pp. 1661-1671, 2010.

[42] N. A. Stanton and M. Pinto, "Behavioural compensation by drivers of a simulator when using a vision enhancement system," Ergonomics, vol. 43, no. 9, pp. 1359-1370, 2000.

[43] S. Winkler, J. Werneke, and M. Vollrath, "Timing of early warning stages in a multi stage collision warning system: drivers' evaluation depending on situational influences," Transportation Research Part F: Traffic Psychology and Behaviour, vol. 36, pp. 57-68, 2016.

[44] F. Bella and R. Russo, "A Collision Warning System for rearend collision: a driving simulator study," Procedia - Social and Behavioral Sciences, vol. 20, pp. 676-686, 2011.

[45] J. D. Lee, J. D. Hoffman, and E. Hayes, "Collision warning design to mitigate driver distraction," in Proceedings Of the 2004 Conference on Human Factors in Computing Systems CHI '04, pp. 65-72, Vienna, Austria, April 2004.

[46] J. D. Lee, D. V. McGehee, T. L. Brown, and M. L. Reyes, "Collision warning timing, driver distraction, and driver response to imminent rear-end collisions in a high-fidelity driving simulator," Human Factors: The Journal of the Human Factors and Ergonomics Society, vol. 44, no. 2, pp. 314-334, 2002.

[47] W. Jianqiang, L. Shengbo, H. Xiaoyu, and L. Keqiang, "Driving simulation platform applied to develop driving assistance systems," IET Intelligent Transport Systems, vol. 4, no. 2 , p. $121,2010$. 